\title{
Get Valid Spirometry Results EVERY Time
}

A Valid Test has:

\section{3 or More Good Curves} and Repeatable FVC and FEVI*

*Use most current American Thoracic Society/ European Respiratory Society (ATS/ERS) standards

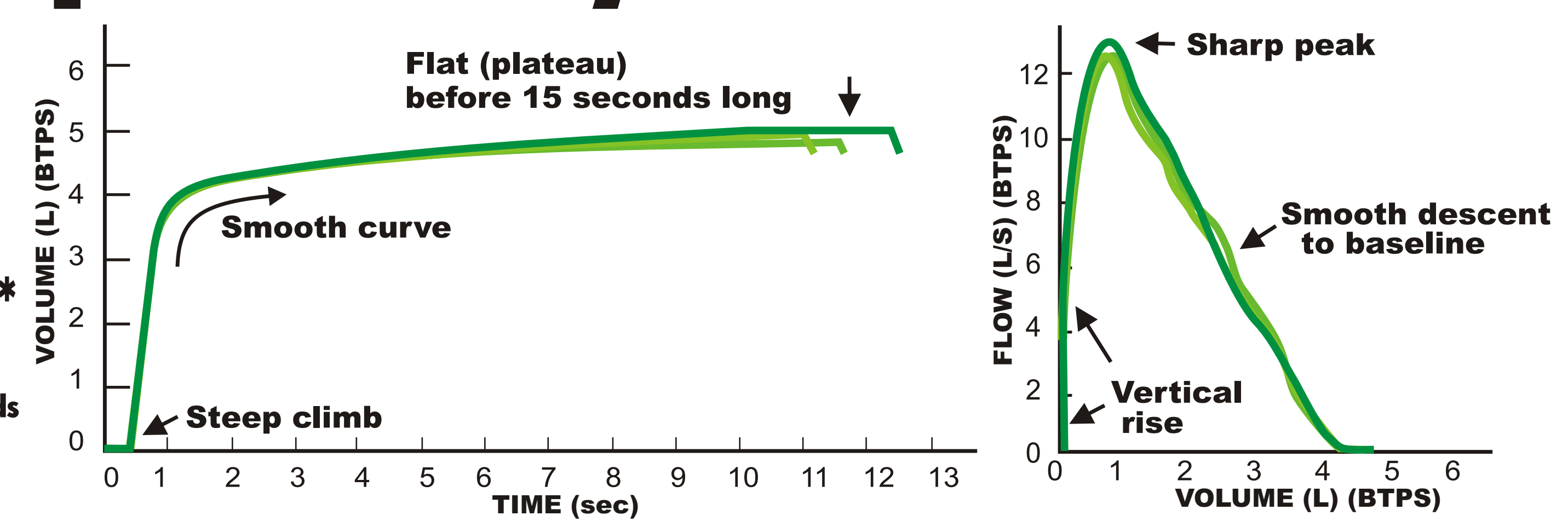

KEY
Green = Good Curve
Bed = Error

\section{HOW TO CORRECT TEST ERRORS}

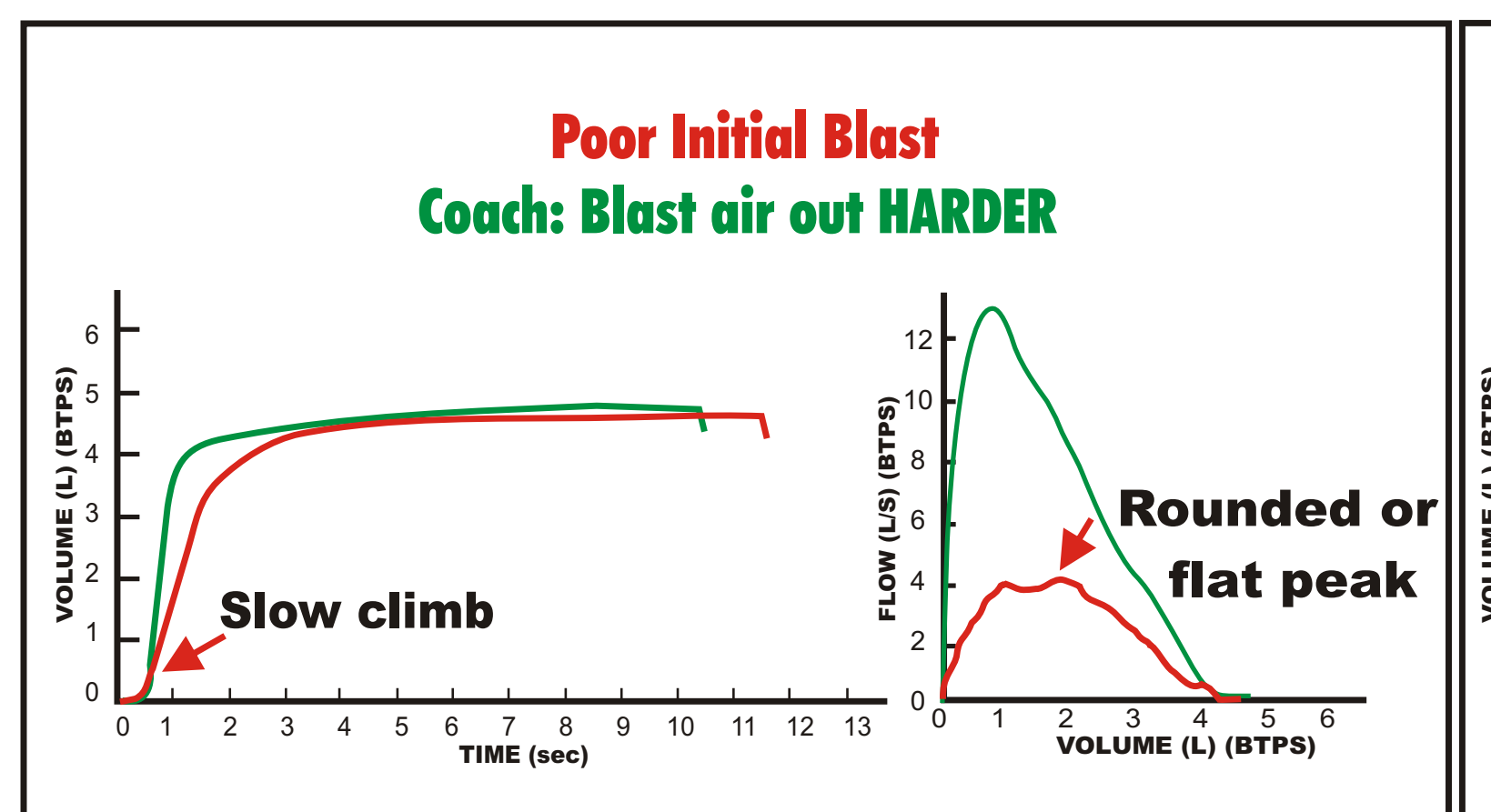

Hesitation; Slow Start; Large Extrapolated Volume Delete Curve; Coach: Blast FASTER

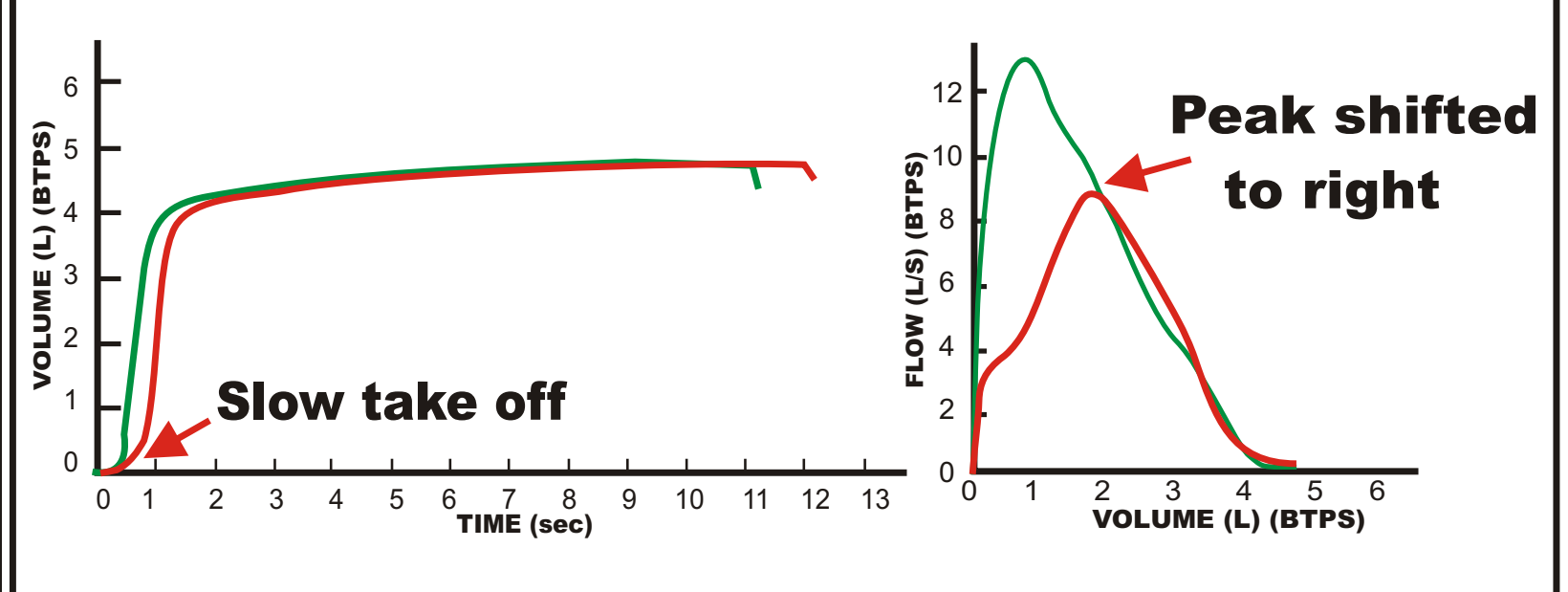

Cough in First Second

Delełe Curve; Correction: Try a drink of water
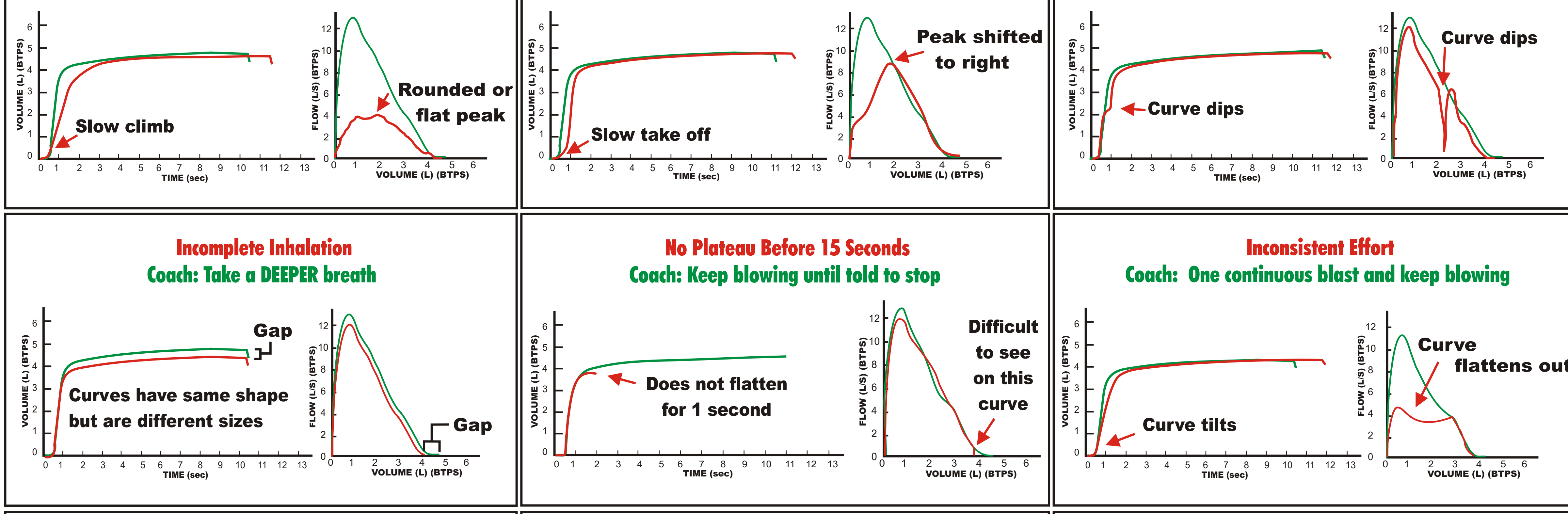

Inconsistent Effort

Coach: One continuous blast and keep blowing

Partially Blocked Mouthpiece

Coach: Position mouthpiece between teeth and on top of tongue; secure dentures

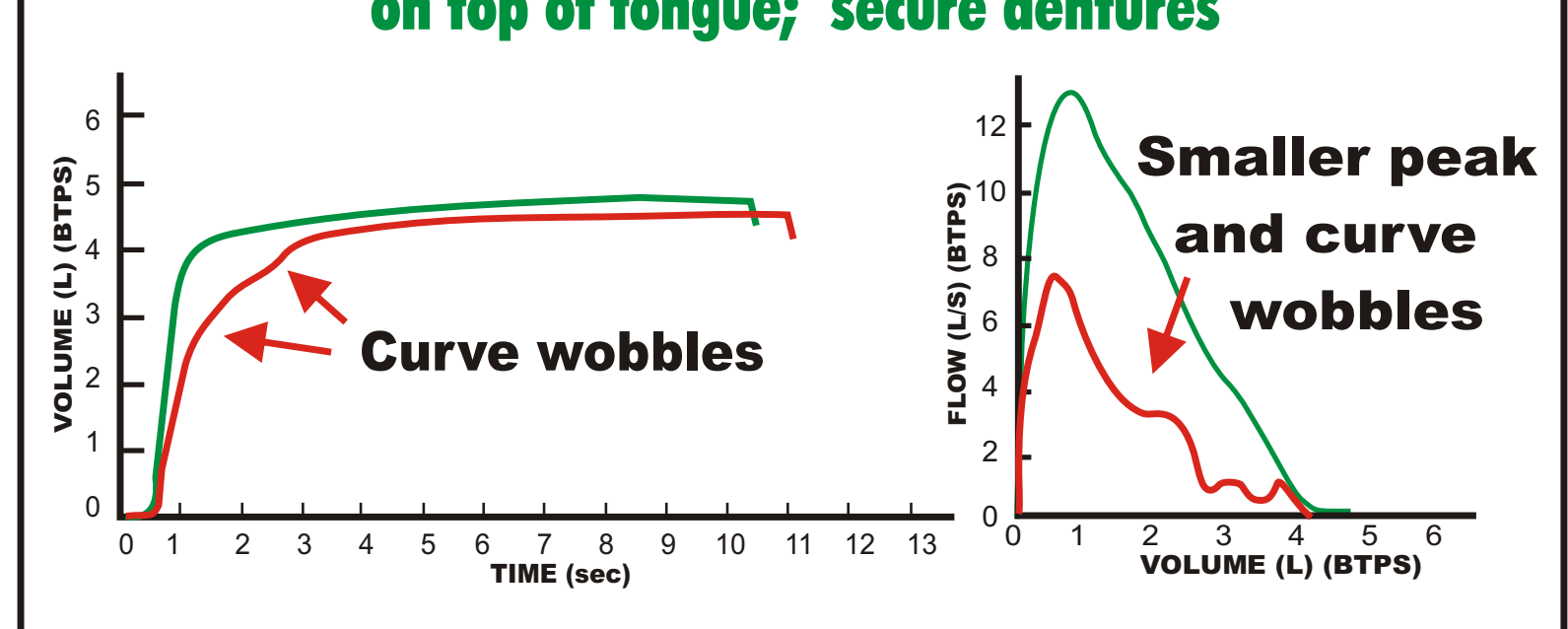

\section{Negative Zero Flow Error}

Correction: No airflow through sensor when spirometer zeroing Hold sensor upright during test
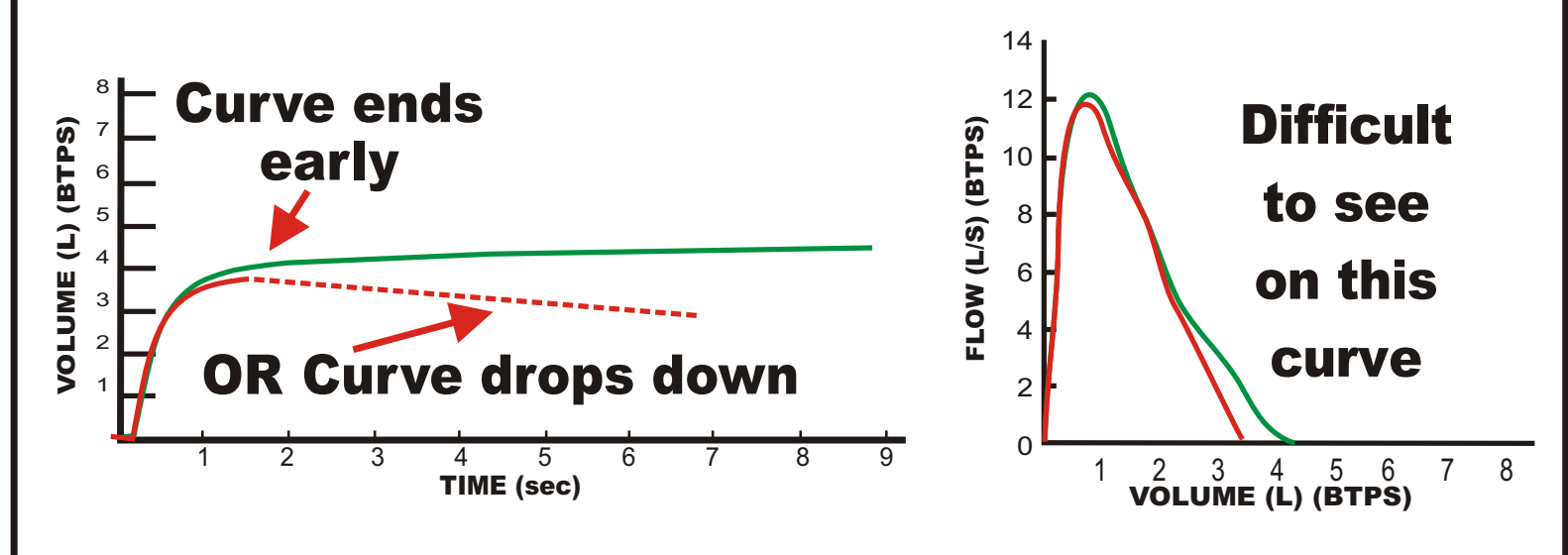

Glottis Closure or Breath Holding Coach: Initial BIG BLAST then RELAX and keep blowing

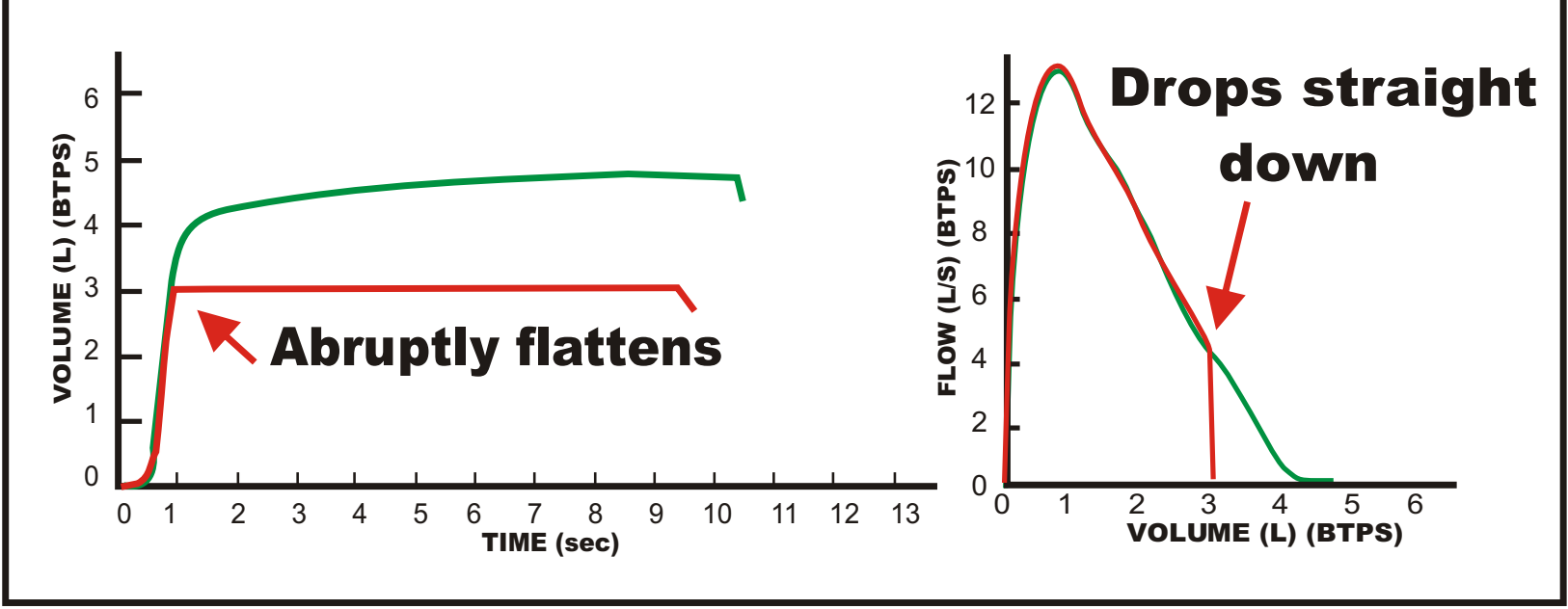

Positive Zero Flow Error

Correction: No airflow through sensor when spirometer zeroing Hold sensor upright during test

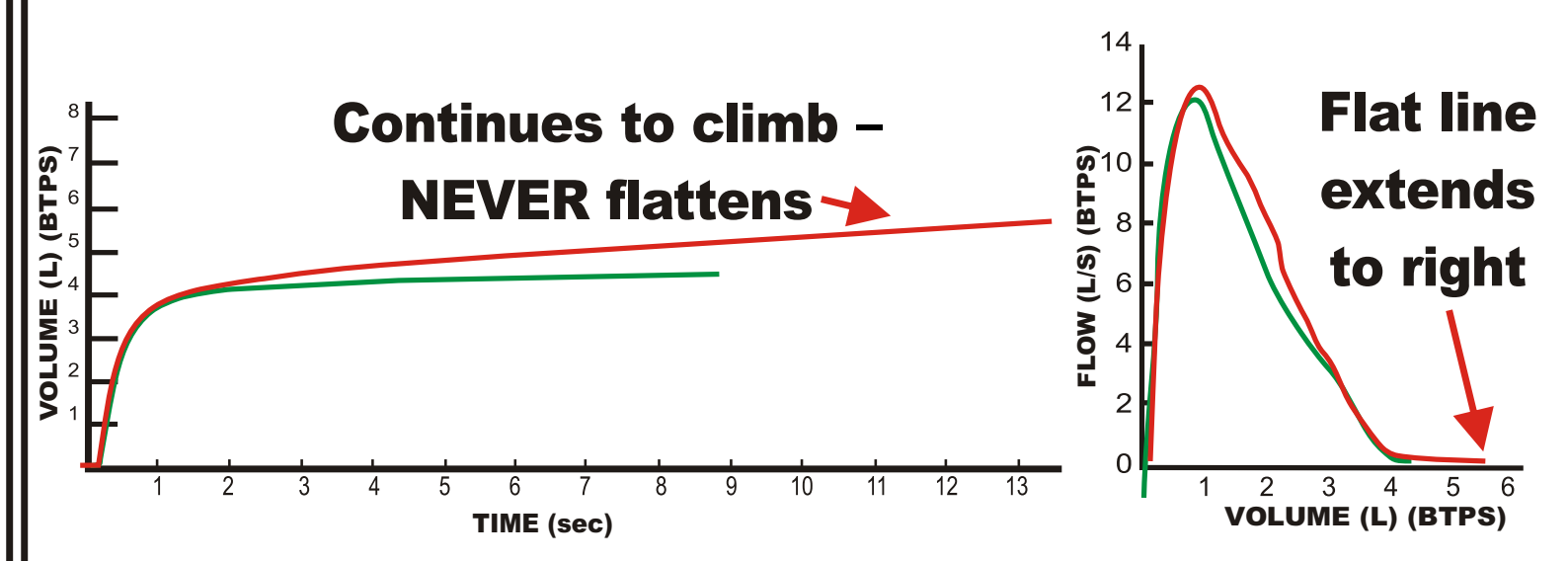

Curve tilts

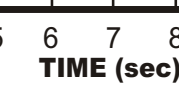

Leak

Correction: Check equipment and connections

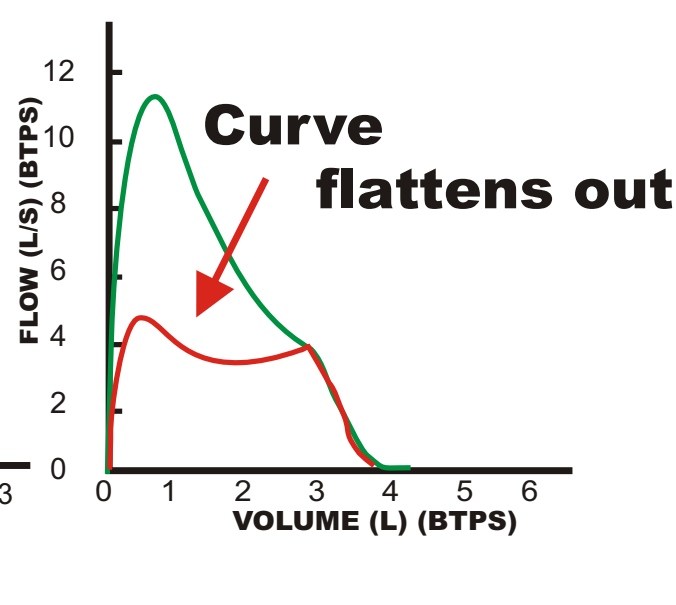

\section{k}

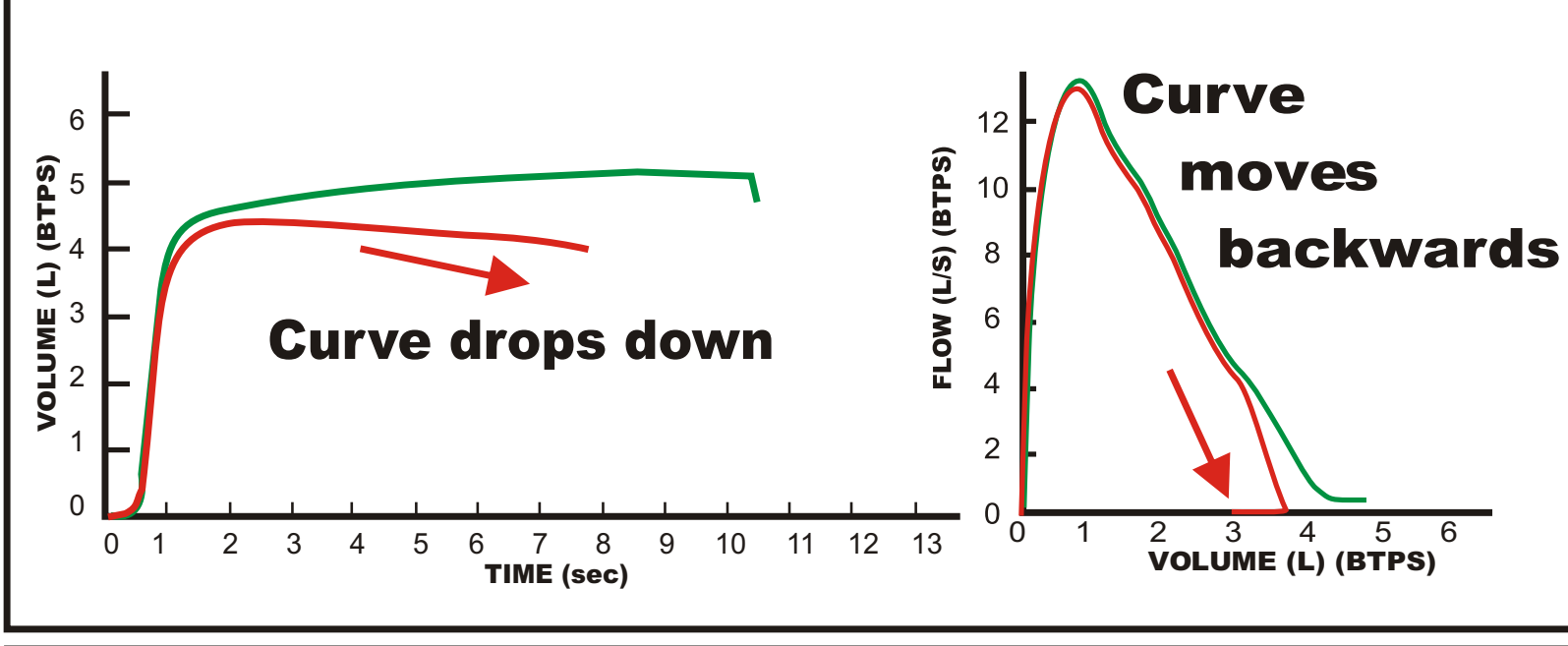

Extra Breaths

Correction: DELETE CURVE; Use nose clips and lips tightly sealed

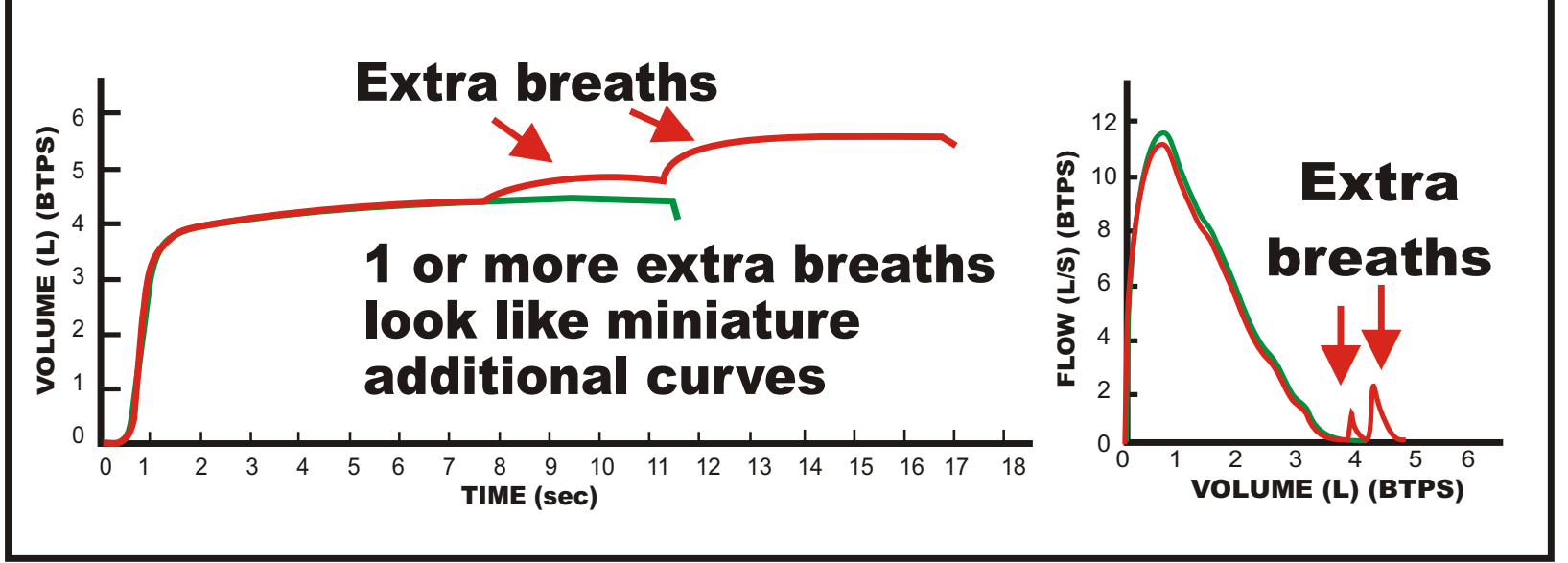

Delivering on the Nation's promise: Safety and healith at work for all people through research and prevention.

To receive documents or more information about occupational safety and health topics, please contact NIOSH:1-800-CDC-INFO (1-800-232-4636) TTY: 1-888-232-6348 email: cdcinfo@cdc.gov or visit the NIOSH Web site at www.cdc.gov/nios For a monthly update on news at NIOSH, subscribe to NIOSH eNews by visiting www.cdc.gov/niosh/eNews. For more information about NIOSH-Approved Spirometry Training go to http://www.cdc.gov/niosh/topics/spirometry/training.html

U.S. Department of Health and Human Services

Centers for Disease Control and Prevention

National Institute for Occupational Safety and Health

\begin{abstract}
SAFER • HEALTHIER • PEOPLE ${ }^{\mathrm{TM}}$
\end{abstract}
DHHS (NIOSH) Publication No. 2011-135
(Q)

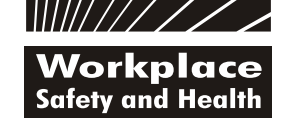

\section{N/osh}

